\title{
LETTERS
}

\section{Medical error and medical assistance in dying}

In a letter to CMAJ in the Oct. 4, 2016 issue, Drs. Dembo and Smith seek to buttress the argument for the expansion of medically assisted dying to other pathologies by stating (with regard to the risk of error) "Nowhere else in medicine do we require zero risk of error." 1,2 It is worth pointing out that in other branches of medicine we are able to learn from our mistakes. Indeed, it is because of this that mistakes are tolerated, and what we learn from them helps us reduce their occurrence in the future.

What is unique about medically assisted dying is that the "treatment" is guaranteed to be successful in $100 \%$ of cases, but accompanied by a $0 \%$ ability to appreciate if a mistake has been made. Because few other medical acts can be accomplished with such impunity, we are likely to become more and more comfortable with it, and more and more permissive as times goes by. As slippery slopes go, this is one where the coefficient of friction also approaches zero.

\section{John C.S. Wootton MD}

General practitioner, Shawville, Que.

Cite as: CMAJ 2017 January 9;189:E31. doi: 10.1503/cmaj.732453

\section{References}

1. Dembo J, Smith D. Assisted dying for patients with psychiatric disorders [letter]. CMAJ 2016;188:1036

2. Kim SYH, Lemmens T. Should assisted dying for psychiatric disorders be legalized in Canada? CMAJ 2016;188:E337-9. 